(C) 2021 UFPB

V.9, n.1, jan./jun. 2021

\title{
EQUIPE EDITORIAL
}

\section{Editoras}

Patrícia Silva, UFPB

Ediane Toscano Galdino de Carvalho, UFPB

\section{Editor de Publicação}

Marcílio Herculano da Costa, UFPB

\section{Consultores/Avaliadores deste número}

Dulce Elizabeth Lima De Sousa, Arquivista, Instituto Federal de Sergipe, IFSE,

Brasil

Edilene Toscano Galdino de Carvalho, UFPB, Brasil

Juliane Teixeira da Silva, UFPB, Brasil

Mônica Tenaglia, UnB, Brasil

Patrícia Silva, UFPB, Brasil

Rayan Aramís de Brito Feitoza, UFPB, Brasil

Archeion Online. Universidade Federal da Paraíba. - Vol. 9, n.1 (jan./jun.

2021)- - João Pessoa : Coordenação do Curso de

Arquivologia/UFPB, 2013-

Revista eletrônica de Arquivologia/UFPB - Semestral - V.9., n.1

Editoras: Patrícia Silva ; Ediane Toscano Galdino de Carvalho

\section{ISSN 2318-6186}

1. Arquivologia. I. Universidade Federal da Paraíba. II. Coordenação do Curso de Arquivologia. III. Título.

CDU 930.25

http://periodicos.ufpb.br/ojs2/index.php/archeion

archeionline@gmail.com 